\title{
The influence of the indentation size in relation to the size of the microstructure of three polycrystalline materials indented with a Berkovich indenter
}

\author{
O. Iracheta, C.J. Bennett, W. Sun
}

Gas Turbine and Transmissions Research Centre, Faculty of Engineering, University of Nottingham, Nottingham NG7 2RD, United Kingdom.

Keywords: Depth-sensing indentation, pile-up, indentation size effect, atomic force microscopy

\begin{abstract}
Three different polycrystalline materials, a fine-grained martensitic steel (CrMoV), a coarsegrained high-purity copper (C110), and a two-phase microstructure titanium alloy (Ti-6Al-4V), have been selected to investigate the heterogeneity of deformation following indentation using a depth-sensing indentation instrument fitted with a Berkovich indenter. The geometry of the pile-up profiles, measured with an atomic force microscope, were observed to be very sensitive to the indentation size with respect to the size of the microstructure and the material properties and crystallographic plane of the indented grain. In contrast, neither the recovery of the area of indentation nor the degree of piling-up were affected by the presence of indentation size effects (ISE). Furthermore, based on the results of a full-3D finite element simulation, it was concluded that the misalignment of the indenter alone does not explain the significantly asymmetric piling-up in highly anisotropic materials, e.g. C110 copper, but that this is due to the crystallographic orientation of the single grain tested. In addition, the experimental results revealed that, although a thicker mechanically hardened layer formed during polishing is more prone to recovery during unloading, leading to a smaller residual indented area, the degree of piling-up is unaffected provided that the ratio of maximum depth $\left(h_{\max }\right)$ to the thickness of the strain-hardened layer is above unity. Moreover, on the same premise, the surface roughness and the thickness of the strain-hardened layer can be discarded as length parameters affecting hardness measurements.
\end{abstract}

\section{Introduction}

The depth-sensing indentation test emerged as a new technique during the early 1980's [1-3] to deal with the mechanical characterisation of elastic properties (Young's modulus and 
hardness) of small volumes of material. The capability of this technique to provide elastic information of the material is achieved by including an unloading stage following the loading stage. The indentation test can be set up either as load or depth controlled; during the load controlled test, the indentation depth, $h$, is recorded as a function of the applied load, $P$, and vice versa during the depth controlled test, such that a load-depth $(P-h)$ curve is generated. Depth-sensing indentation testing is categorised by ISO 14577 [4] as follows:

- Macroindentation: $2 \mathrm{~N} \leq P_{\max } \leq 30 \mathrm{kN}$

- Microindentation: $P_{\max }<2 \mathrm{~N}$ and $h_{\max }>0.2 \mu \mathrm{m}$

- Nanoindentation: $h_{\max } \leq 0.2 \mu \mathrm{m}$

where $P_{\max }$ and $h_{\max }$ are the maximum indentation load and depth respectively. Notwithstanding, the indentation scale is meaningless if the effects of the microstructural size parameters on the mechanical response of the indented material are unknown, i.e. indentation size effects (ISE). Numerous examples of materials exhibiting ISE on the measured hardness as the load is decreased have been published in the literature [5-7], however, the mechanism by which ISE are produced remains a subject of considerable dispute. Fleck et al. [8] attributed the enhanced hardening to the accumulation of geometrically necessary dislocations (GND), in addition to the statically stored dislocations (SSD), generated during the large strain gradients inherent in small indentations. Li et al. [9] concluded that friction is a major component of ISE, the contribution of which is inversely proportional to the indentation size. Furthermore, the hardness-depth dependence has been found to be influenced by experimental artefacts, such as friction, the effects of surface hardening (e.g. due to mechanical polishing [7]) and tip imperfections [6, 10]. Sargent [11] presented several examples of mechanisms that produced ISE such as surface oxidation or contamination, the effect of anisotropy in single crystals and temperature. Lim and Chaudhri [12] attributed the increase in the measured hardness of high-purity polycrystalline metals to the initial dislocation densities rather than to the variation in grain size. They also concluded that different crystallographic orientations of single-crystals or contiguous grains are unlikely to cause an effect on hardness. In contrast, Stelmashenko et al. [13] provided evidence of the sensitivity of the mechanical response to indentation to the crystallographic orientation of the indented surface and the orientation of the edges of the indenter with respect to the crystallographic directions. At loads below $100 \mathrm{mN}$, the hardness on the (100) surface of single crystals of high-purity tungsten exhibited 
significantly higher values compared to those measured on the (111) surface, while at loads beyond $10 \mathrm{~N}$ the difference vanished, although the hardness remained dependent on the indentation load. Moreover, topographic measurements taken with a scanning tunnelling microscope revealed a significantly higher pile-up on the (100) surface compared with the other two planes tested, namely (110) and (111). Wang et al. [14] and Kucharski et al. [15] reported an out-of-plane displacement mechanism on the primary slip plane on indentations performed with a conical and Berkovich indenter, respectively. Their experimental data concluded that at low loads, the angular position of the pile-up patterns first correspond with the tip geometry and as the load is increased, the position rotates about the indentation axis until at sufficiently deep indentation depths, the symmetry of the pile-up patterns correspond with the crystallographic orientation of the indented surface, e.g. the [10 $\overline{1}],[01 \overline{1}]$ and [ 110$]$ directions on a (111) surface. Surprisingly, although it is typically accepted that the sinking-in deformation mode is predominant in materials with a high strain hardening behaviour [16], such as the copper studied by Wang et al. [14] and Kucharski et al. [15], the occurrence of sinking-in was not reported in these studies, instead, the piling-up of material was explained [14] by the rather small local strain hardening resulting from the activation of only a small set of slip systems that accounts for most of the local deformation.

The above brief background clearly shows that the local plastic behaviour of the material beneath the indenter may be distant from that of a continuum isotropic material. Therefore, the current investigation reports on the effects of some of the experimental parameters established in a conventional depth-sensing indentation programme on the topography of the residual imprint left by a Berkovich indenter on three polycrystalline materials, namely a CrMoV steel, C110 copper and Ti-6Al-4V. The experiments highlight the necessity of understanding the effects of size parameters on the mechanical response to indentation prior to any attempt to interpret the extracted data.

\section{Experimental and numerical methods}

\subsection{Materials and metallographic preparation}

Three materials with different elastic-plastic behaviours and microstructure have been selected for this study. These materials include a steel (CrMoV), a titanium alloy (Ti-6Al-4V) and an oxygen-free high purity copper $(\mathrm{C} 110)$. $\mathrm{CrMoV}$ steel was used in the tempered condition and therefore the as-received sample was austenitised at $940{ }^{\circ} \mathrm{C}$ for 45 minutes, oil quenched and tempered at $570{ }^{\circ} \mathrm{C}$ for 120 minutes. The material composition is included in Table 1. 
Table 1. Chemical composition of studied materials

(weight \%) as per a) Columbia metals, b) Aircraft materials and c) VSMPO-Trius.

\begin{tabular}{|c|c|c|c|}
\hline & $\mathrm{C} 110^{\mathrm{a}}$ & $\mathrm{CrMoV}^{\mathrm{b}}$ & Ti-6Al-4V \\
\hline $\mathrm{Cu}$ & 99.99 & - & - \\
\hline $\mathrm{Pb}$ & 0.001 & - & - \\
\hline $\mathrm{P}$ & 0.0003 & 0.020 & - \\
\hline S & 0.002 & 0.020 & - \\
\hline $\mathrm{C}$ & - & $0.35-0.43$ & - \\
\hline $\mathrm{Si}$ & - & $0.10-0.35$ & - \\
\hline $\mathrm{Cr}$ & - & $3.0-3.5$ & - \\
\hline Mo & - & $0.80-1.10$ & - \\
\hline $\mathrm{Ni}$ & - & $0.30 \max$ & - \\
\hline $\mathrm{Sn}$ & - & 0.03 & - \\
\hline $\mathrm{Mn}$ & - & $0.40-0.70$ & 0.01 \\
\hline $\mathrm{V}$ & - & $0.15-0.25$ & 4.04 \\
\hline $\mathrm{Ti}$ & - & - & 88.83 \\
\hline $\mathrm{Fe}$ & - & - & 0.14 \\
\hline $\mathrm{Al}$ & - & - & 6.85 \\
\hline $\mathrm{Nb}$ & - & - & 0.03 \\
\hline
\end{tabular}

Indentation specimens of $\mathrm{CrMoV}$, Ti-6Al-4V and $\mathrm{C} 110$ were mounted in a conductive resin and then ground with abrasive paper down to 1200 grit $(15.3 \mu \mathrm{m})$, followed by polishing with 5 and $1 \mu \mathrm{m}$ diamond suspension. Ultimately, specimens were polished with colloidal silica down to $0.06 \mu \mathrm{m}$ for a minimum of 20 minutes in order reduce the size of the hardened layer formed due to mechanical polishing. The final polishing with colloidal silica was omitted in one of the CrMoV samples in order to assess the sensitivity of the depth-sensing indentation data to the thickness of the mechanically-hardened layer formed during polishing. This material was selected for assessment as the fine microstructure, compared to those of the Ti-6Al-4V and $\mathrm{C} 110$, is expected to have less influence on the experimental data.

In order to better understand the influence of the microstructure on indentation, an additional set of specimens were etched after polishing as follows: CrMoV steel using 5\% Nital for $50 \mathrm{~s}$, Ti-6Al-5V with Kroll's reagent (1.5 mL HF, 4mL $\mathrm{HNO}_{3}$ and $94 \mathrm{~mL} \mathrm{H}_{2} \mathrm{O}$ ) for $10 \mathrm{~s}$, and $\mathrm{C} 110$ 
with a solution consisting of $5 \mathrm{~g} \mathrm{Fe}\left(\mathrm{NO}_{3}\right)_{3}, 25 \mathrm{~mL} \mathrm{HCl}$ and $70 \mathrm{~mL}$ distilled water for $20 \mathrm{~s}$. The microstructures were observed using a Nikon Eclipse LV100ND optical microscope and a Phillips XL30 ESEM-FEG scanning electron microscope (SEM) using both secondary (SE) and backscattered (BSE) electron diffraction.

\subsection{Depth-sensing indentation test}

Depth-sensing indentation tests were conducted using a NanoTest ${ }^{\mathrm{TM}} \mathrm{NTX}$ instrument equipped with a Berkovich indenter. A new Berkovich diamond indenter with a tip radius of less than 20 $\mathrm{nm}$ was used to perform the indentations. Sample fixtures may add to the compliance of the instrument and thus, cyanoacrylate adhesive was used to glue the mounted sample to the instrument holder. Before testing, both the indenter area function and the load frame compliance were calibrated using a standard sample of fused silica in compliance with ISO 14577 [4]. In order to remove the effects of surface roughness on the results, indentation loads were selected to reach maximum indentation depths of at least 20 times the average roughness $\left(R_{a}\right)$ of the specimen in accordance with ISO14577 [4]. Given that the polishing procedure affects the surface of the specimen to a depth of about the same size as the nominal grit due to strain-hardening or cold-working [16], indentations were performed at sufficient load to ensure indentation depths of at least three times the thickness of the strain-hardened layer as suggested by Liu et al. [7]. Therefore, the indenter has been loaded from an initial contact force $\left(P_{i}\right)$ of $0.1 \mathrm{mN}$ to a maximum force $\left(P_{\max }\right)$ within the range of $30-480 \mathrm{mN}$ at a loading and unloading rate of $10 \mathrm{mN} / \mathrm{s}$ for CrMoV and Ti-6Al-4V. C110 on the other hand was loaded and unloaded at a rate of $4 \mathrm{mN} / \mathrm{s}$ in order to obtain a similar number of data points, considering that this material is indented with less than half the load of all other materials. In specimens of CrMoV, a dwell period of $30 \mathrm{~s}$ at $P_{\max }$ was applied so as to ensure the unloading data used for analysis purpose were mostly elastic. In addition, the load was held constant for a period of $30 \mathrm{~s}$ at $0.1 P_{\max }$ to establish the rate of displacement produced by thermal expansion in the system, that is, thermal drift. Therefore, thermal drift corrections were performed in addition to these curves. However, this load-time sequence was avoided in C110 and Ti-6Al-4V and instead, a single loading and unloading ramp was defined. In order to assess the sensitivity of the $P-h$ curves to the loading-unloading rate, an extra set of indentations in Ti-6Al-4V at a rate of 1.5 $\mathrm{mN} / \mathrm{s}$ were performed. Sets of five indentations were performed per indentation test at an offset of at least 20 times the maximum depth, as suggested by ASM International [17], in order to avoid overlapping of plastic strain-hardened zones. Table 2 provides details of the parameters used in each set of indentations. 


\begin{tabular}{|c|c|c|c|c|c|c|}
\hline \multirow{3}{*}{\multicolumn{2}{|c|}{$\begin{array}{c}\text { Specimen } \\
\text { L-U rate }[\mathrm{mN} / \mathrm{s}] \\
\text { Polishing }[\mu \mathrm{m}]\end{array}$}} & \multicolumn{2}{|c|}{ Ti-6Al-4V } & \multirow{2}{*}{\multicolumn{2}{|c|}{$\begin{array}{c}\text { CrMoV } \\
10\end{array}$}} & \multirow{3}{*}{$\begin{array}{c}\text { C110 } \\
4 \\
0.06\end{array}$} \\
\hline & & \multirow{2}{*}{$\begin{array}{c}10 \\
0.06\end{array}$} & \multirow{2}{*}{$\begin{array}{c}1.5 \\
0.06\end{array}$} & & & \\
\hline & & & & 0.06 & 1 & \\
\hline \multirow{8}{*}{$2^{\rightleftarrows}$} & 480 & $\checkmark$ & & & & \\
\hline & 360 & $\checkmark$ & & & & \\
\hline & 240 & $\checkmark$ & & $\checkmark$ & $\checkmark$ & \\
\hline & 180 & & & $\checkmark$ & $\checkmark$ & \\
\hline & 120 & $\checkmark$ & & $\checkmark$ & $\checkmark$ & $\checkmark$ \\
\hline & 60 & & & & & $\checkmark$ \\
\hline & 36 & & & & & $\checkmark$ \\
\hline & 30 & $\checkmark$ & $\checkmark$ & $\checkmark$ & & \\
\hline
\end{tabular}

In order to bridge the gap between the micro- and macro-scale properties, microhardness measurements at decreasing loads have been performed with the aim of determining the load independent hardness, i.e. the macroscopic hardness. Therefore, a Vickers microhardness test has been carried out at indentation loads over the range of 25 to 1000 gram force in specimens of Ti-6Al-4V, CrMoV and C110. Hardness measurements at loads below 100 gram force in CrMoV were neglected as the indentation impressions exceeded the limits of spatial resolution of the built-in optical microscope. Five indentations per load were performed at an offset of at least three times the diagonal of the residual imprint. The macroscopic hardness was compared with the Martens hardness computed from each $P$ - $h$ curve in order to assess the suitability of a depth-sensing indentation experiment to represent the mechanical behaviour of the bulk material, or otherwise.

\subsection{Surface topographic measurements}

The residual imprints of the indents of interest were measured using a Bruker FastScan Bio Icon atomic force microscope (AFM) in peak force mode. As it was impractical to analyse every indentation for a given set of indentation parameters, surface topography measurements were taken only from the indents which exhibited the highest (HS) and lowest (LS) stiffness for each set of indentations. Owing to the equivalency of the projected areas, the same parameters were defined to measure the surface topography regardless of the material, i.e. 512 lines of 512 sample data points per scan line, scanned in a squared frame between 20 to $25 \mu \mathrm{m}$ 
at a scan rate of half a line per second $(0.5 \mathrm{~Hz})$. The $\mathrm{Z}$ step height of the FastScan head is limited to $\pm 3 \mu \mathrm{m}$. Bruker RTESPA-300 etched silicon probes with tip radii in the range 8 to $12 \mathrm{~nm}$, as per manufacturers' specifications, were used. A cantilever coated with Al reflective was employed, as recommended for highly reflective samples, with a spring constant of 40 $\mathrm{N} / \mathrm{m}$. Before analysing the height measurements, a first-order plane fit was applied to the heights of each pixel in the image in order to correct for tilting. Line profiles in each direction of the bisector of the side of the triangular impression were extracted in order to assess the symmetry of the indentation imprint. In order to measure the actual area of indentation, a bearing analysis was conducted to quantify the percentage of the surface (the "bearing ratio") that lies above or below a reference plane [19], i.e. the bearing depth. Roughness statistics were reported from areas neighbouring the residual imprint following the ISO 4287/1-1997 [18] standard.

\subsection{Finite element modelling of indentation}

The sensitivity of the pile-up to the degree of misalignment between the normal to the surface and the centreline of the indenter was investigated by numerically simulating the indentation test of a bulk metal with a Berkovich indenter, using a 3D Finite Element (FE) model (ABAQUS Standard 6.12-3). The FE model simulates the full domain of a load-controlled test. The Berkovich indenter has been modelled as a 3D discrete rigid body using 3-node 3D rigid triangular facet elements (R3D3 in ABAQUS). The specimen was defined as a 3D deformable body and has been discretised using linear hexahedral elements with reduced integration points (C3D8R in ABAQUS). Beneath the indenter, where steep strain gradients are expected, a higher element density has been defined based on the results of a mesh sensitivity study. Boundary conditions in the deformable body (specimen) are defined as follows: the nodes in the bottom of the domain (plane $I$ ) are constrained in the three directions ( $\mathrm{U} 1=\mathrm{U} 2=\mathrm{U} 3=0)$, the cylindrical surface $I I$ is traction free and the displacement of the nodes of plane $I I I$, that come in contact with the indenter, is governed by a master-slave surface-to-surface boundary condition that considers the shape of both the slave and master surfaces in the region of contact. The master-slave contact interaction between the indenter (master) and the specimen surface (slave) was defined with zero contact friction since the effect of friction on the indentation process can be assumed negligible [20]. The contact constraints are imposed according to a penalty method in which a large penalty stiffness coefficient is used to minimize the penetration of the slave surface into the master surface at the constraint locations. A sufficiently large domain has been adopted to model a semi-infinite deformable body such that the solution 
results insensitive to the far-field effects. To validate this assumption, traction free nodes (surface $I I$ ) were constrained with roller boundary conditions such that displacements are only allowed along the axis of indentation $(\mathrm{U} 1=\mathrm{U} 3=0)$. The motion of the rigid body is determined by a reference point (RP) located at a node in the tip of the Berkovich indenter and therefore the loading and boundary conditions associated with the indenter have been assigned to this point. The RP, and therefore the indenter, is only allowed to translate in the vertical direction $(\mathrm{U} 1=\mathrm{U} 3=\mathrm{UR} 1=\mathrm{UR} 2=\mathrm{UR} 3=0)$. An elastic-perfectly plastic material model and a ratio of Young's modulus to yield stress $\left(E / \sigma_{\mathrm{y}}\right)$ of approximately 150 was assumed so as to promote a piling-up deformation mode.

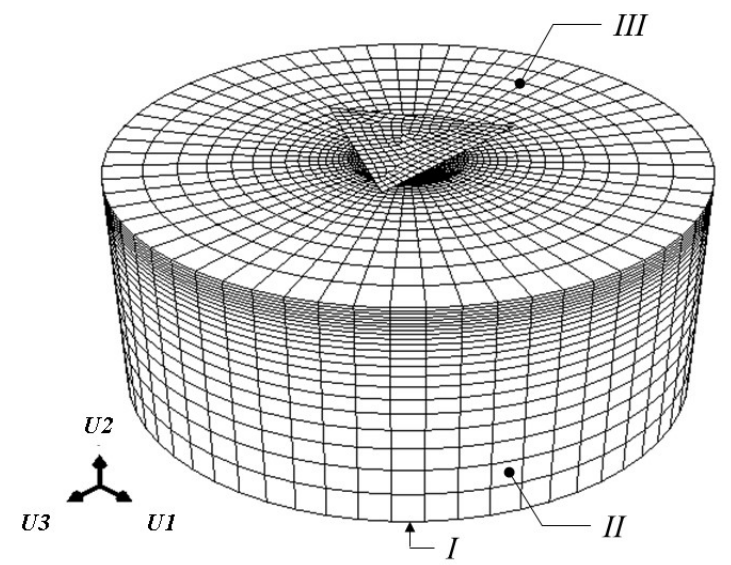

Figure 1. Geometry and boundary conditions defined in the $3 \mathrm{D}$ indentation model.

\section{Results and discussion}

\subsection{Macroscopic hardness}

$\mathrm{C} 110$, as observed in Figure 2a, is a polycrystalline high purity copper with a microstructure consisting of equiaxed grains with sizes ranging from 30 to $100 \mu \mathrm{m}$. As observed in Figure $2 \mathrm{~b}$, $\mathrm{CrMoV}$ in the fully heat-treated condition exhibits tempered martensite as white spherodized precipitates of cementite $\left(\mathrm{Fe}_{3} \mathrm{C}\right)$ sitting on the lath packets [21]. The metallography in Figure $2 \mathrm{c}$ shows the two-phase microstructure of Ti-6Al-4V, which is comprised by an equiaxed $\alpha$ phase and an intergranular $\beta$ phase. As determined in the SEM by backscattered electron diffraction, the size of the (darker) $\alpha$-grains is between 20-30 $\mu \mathrm{m}$. Under the action of an external load, the average properties of the measured individual grains define the constitutive behaviour of the material tested and thus, a typical microindentation Vickers hardness can provide information on the dependency of the material to microstructural length parameters. 
a)

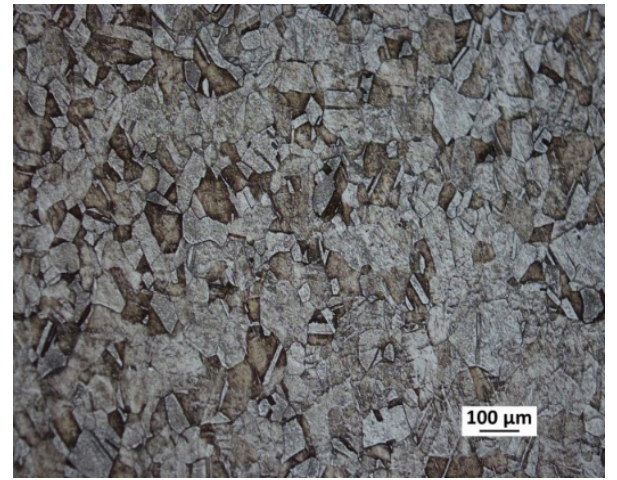

b)

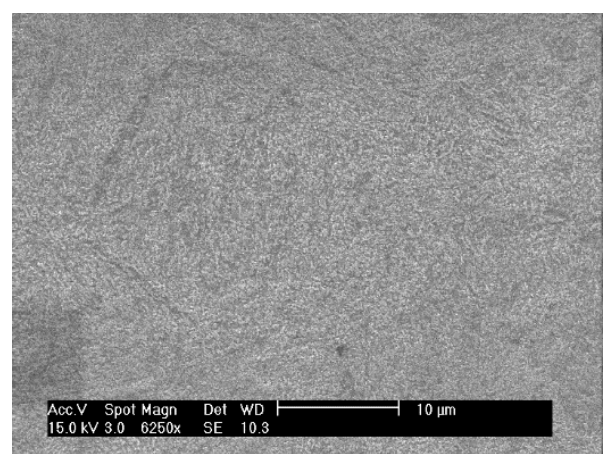

c)

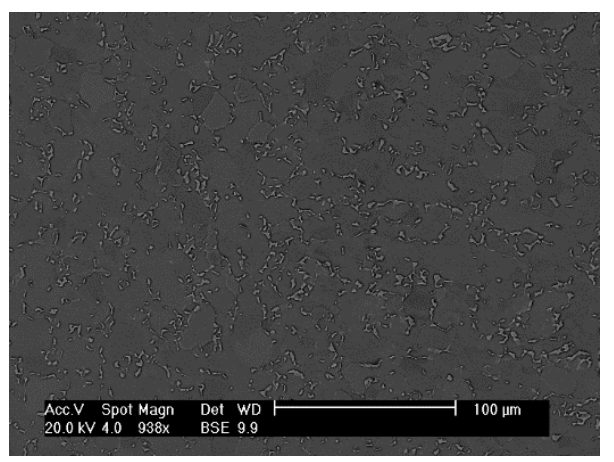

Figure 2. Microstructure as observed a) in $\mathrm{C} 110$ by optical microscopy and by SEM in b) $\mathrm{CrMoV}$ and c) Ti-6Al-4V.

The Vickers microhardness test measured near constant hardness values of $95 \pm 4.3 \mathrm{kgf} / \mathrm{mm}^{2}$ at loads ranging from 25 to 1000 gram force in C110, and $484 \pm 12.7 \mathrm{kgf} / \mathrm{mm}^{2}$ within a load range of 100 to 1000 gram force in $\mathrm{CrMoV}$ as shown in Figure $3 \mathrm{a}$ and $\mathrm{b}$, respectively. In contrast, the hardness of Ti-6Al-4V shows a clear dependence on the magnitude of load as observed in Figure 3c. Less scattered data is observed as the load increases, as the number of grains measured increases and possibly due to hardness being less sensitive to other factors that contribute to ISE, such as surface roughness and tip roundness. It is also noticeable that within the range of loads covered by the microhardness tester ( $\mathrm{P}<1000 \mathrm{gf})$, the hardness magnitude never converges to a constant value. Therefore, using a macrohardness tester loaded with loads of 2.5 and $30 \mathrm{kgf}$ it was concluded that a hardness of $312.2 \mathrm{HV}_{2.5}$ can be taken as load- 
independent as indicated by the dashed line in Figure 3c. In addition, considering only the hardness values at their respective highest test load, a mean Vickers hardness of $481.8 \mathrm{HV}_{1.0}$ for $\mathrm{CrMoV}, 97.1 \mathrm{HV}_{1.0}$ for $\mathrm{C} 110$ is observed to be load-independent.

a)
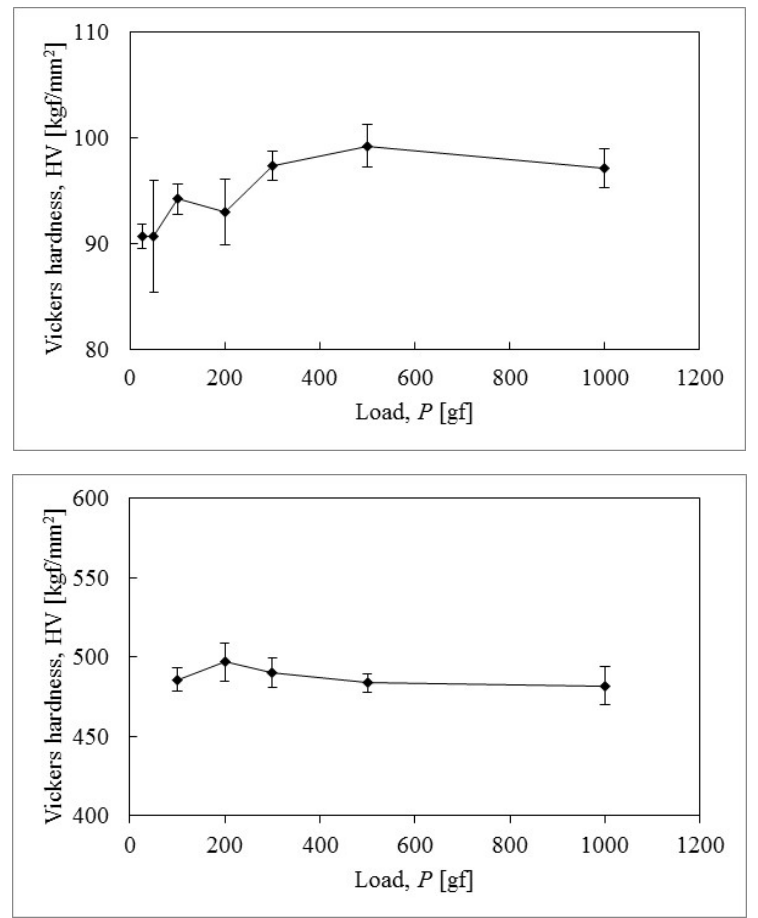

b)

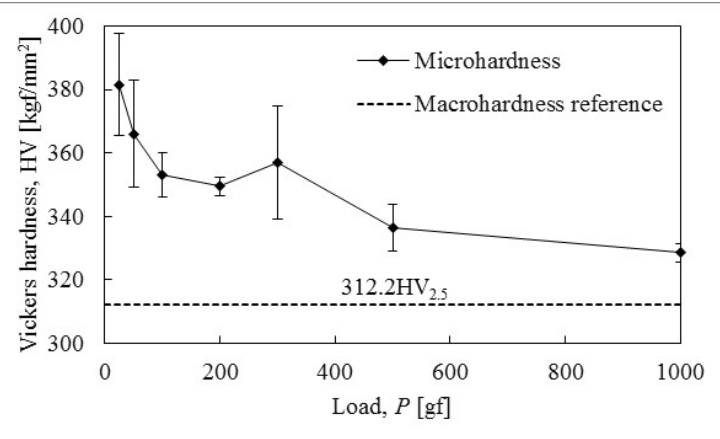

Figure 3. Sensitivity of hardness value to the indentation load for a) $\mathrm{C} 110, \mathrm{~b}) \mathrm{CrMoV}$ and c) Ti-6Al-4V. Error bars represent 1 standard deviation.

\subsection{Depth-sensing indentation data}

The raw load-depth data and computed Martens hardness (HM) at different $P_{\max }$ values are presented for the three materials studied in Figure 4. Due to the inhomogeneity in the specimen material and measurement errors, each set of indentations comes associated with uncertainties, which consequently result in scatter or variability in the collected data as observed in the left column of Figure 4. As observed in the right column of Figure 4, the variability of HM tends to decrease as the indentation load increases in the same way as observed in the microhardness 
measurements. It can be seen that, in all three materials, indentation size effects (ISE) are still significant even at the maximum load tested for the specimens of Ti-6Al-4V, CrMoV steel and particularly in C110 copper as inferred by the deviation of the measured HM from the loadindependent hardness value, i.e. 1.5, 13.5 and $40 \%$ respectively. The extra set of indentations performed in Ti-6Al-4V at a significantly lower loading and unloading rate $(1.5 \mathrm{mN} / \mathrm{s})$ shows a lack of sensitivity to strain rate as illustrated in Figure 4f; reducing the strain rate, as derived by $\dot{\varepsilon}=\frac{d h_{p}}{d t} \frac{1}{h_{p}}[16]$, by as much as $84 \%$ results in a hardness difference of less than $1.6 \%$. The variability of the data also appears insensitive to the indentation strain rate at this indentation load, yet error bars are not included for clarity. 


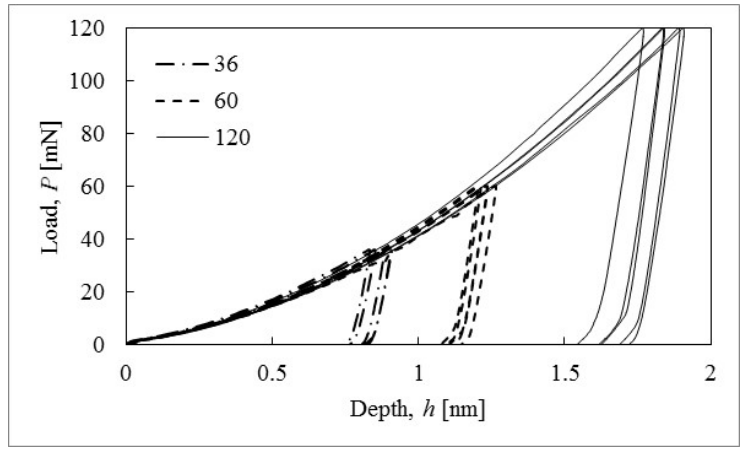

a)

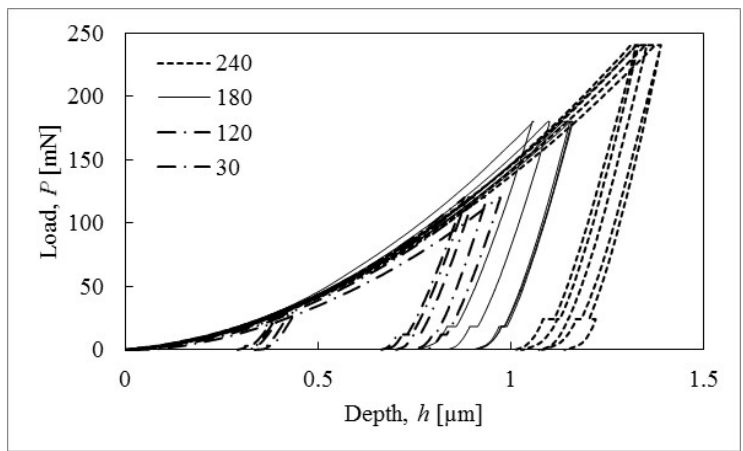

c)

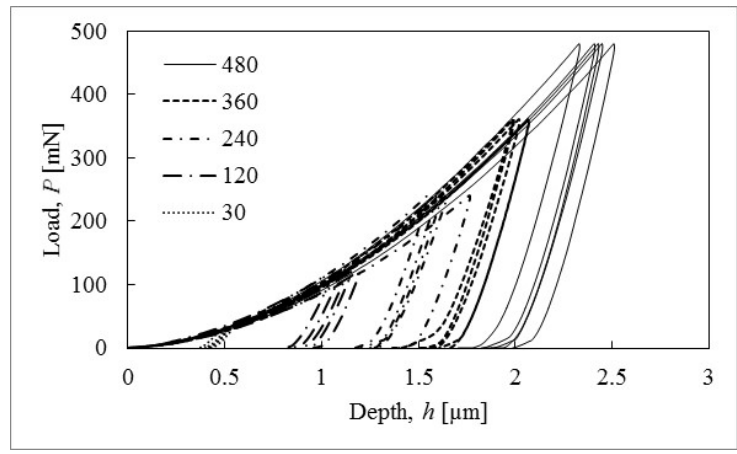

e)

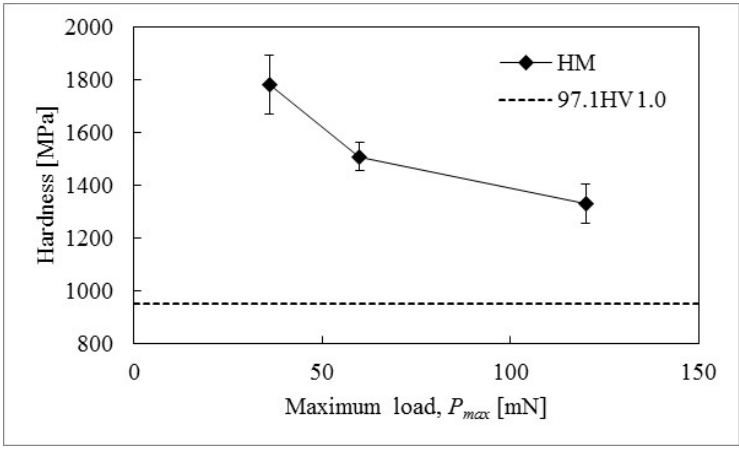

b)

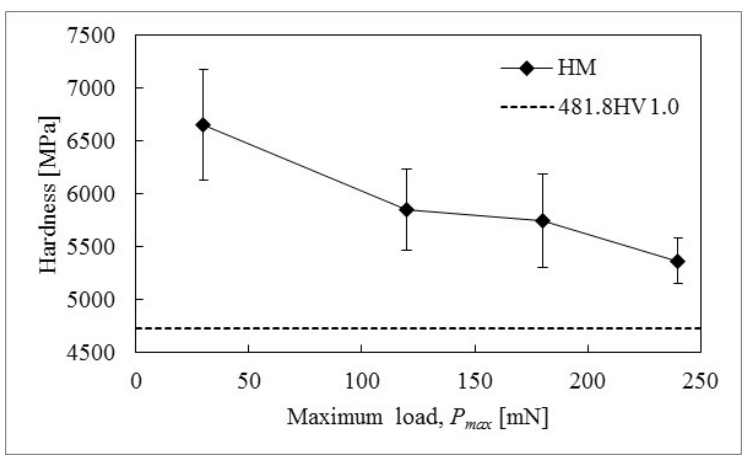

d)

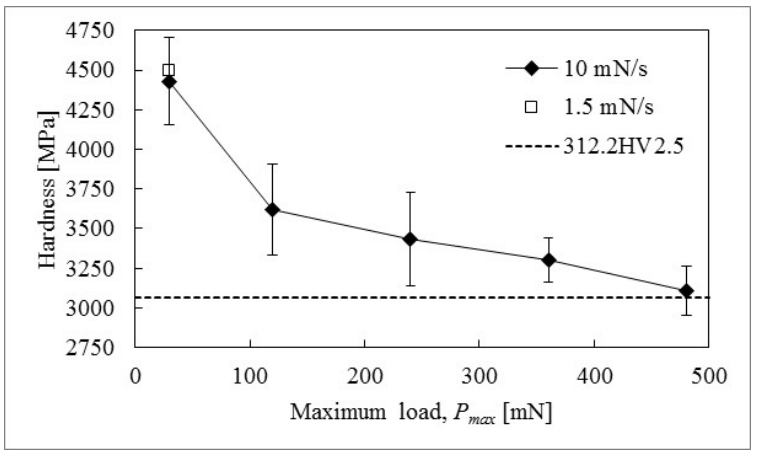

f)

Figure 4. Indentation $P$ - $h$ curves (left) and calculated Martens hardness (right) for a, b) C110 copper, c, d) CrMoV steel and e, f) Ti-6Al-4V. Error bars are one standard deviation.

On top of ISE, length parameters affecting the measured hardness value may be introduced by the condition of the surface of the specimen. Figure 5 shows the AFM scan of the surface topography resulting from two different mechanical polishing procedures. Although the surface after polishing using $1 \mu \mathrm{m}$ diamond suspension appears to be very rough, the average roughness $\left(R_{a}=4.98 \mathrm{~nm}\right)$ is negligible compared with the indentations performed in $\mathrm{CrMoV}$ steel, i.e. $h_{\max }>400 \mathrm{~nm}$. As per ISO14577 [4], at indentations depths beyond $20 R_{a}$ the effects of surface roughness are negligible. 
a)

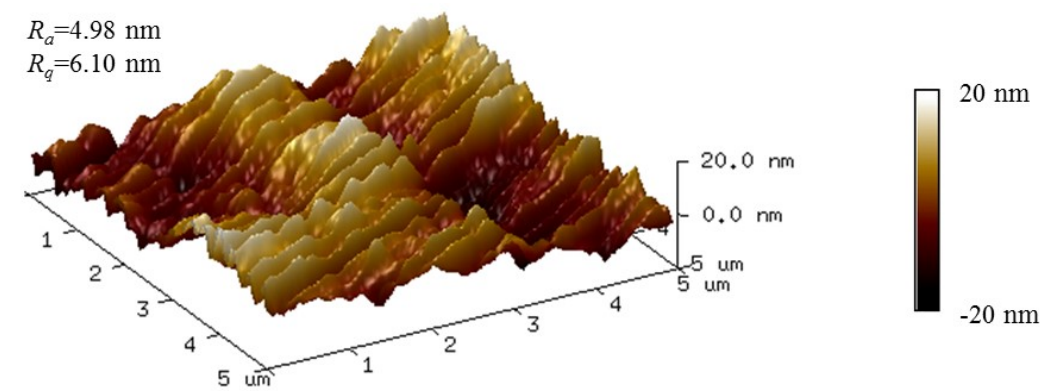

b)

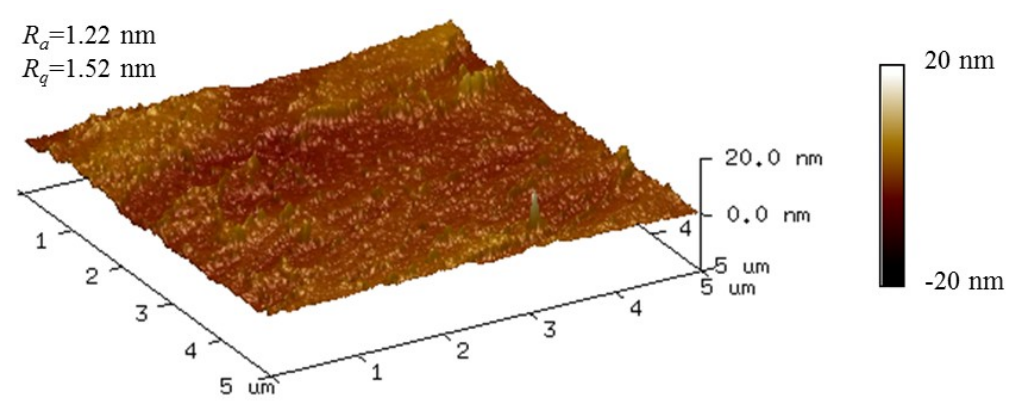

Figure 5. AFM topography of $\mathrm{CrMoV}$ steel surface after mechanical polishing using a) $1 \mu \mathrm{m}$ diamond suspension and b) $0.06 \mu \mathrm{m}$ colloidal silica.

Furthermore, Figure 6 suggests that the effects of the metallographic procedure, i.e. surface roughness and the thickness of the strain-hardened layer, can be discarded as length parameters affecting hardness measurements. This is somewhat expected as the maximum indentation depths reached in these experiments are between 0.9 to $1.4 \mu \mathrm{m}$. The deviation in HM between polishing procedures is within experimental error and hence error bars are excluded for clarity. Notwithstanding, this outcome is based on the strain-hardened surface of $\mathrm{CrMoV}$, a material with moderate capacity to strain-harden $(n \sim 0.1)$. In contrast, the near surface hardness value of materials with high capacity for strain-hardening, such as annealed high purity copper ( $n \sim$ 0.45), are more sensitive to the surface polishing procedure [7].

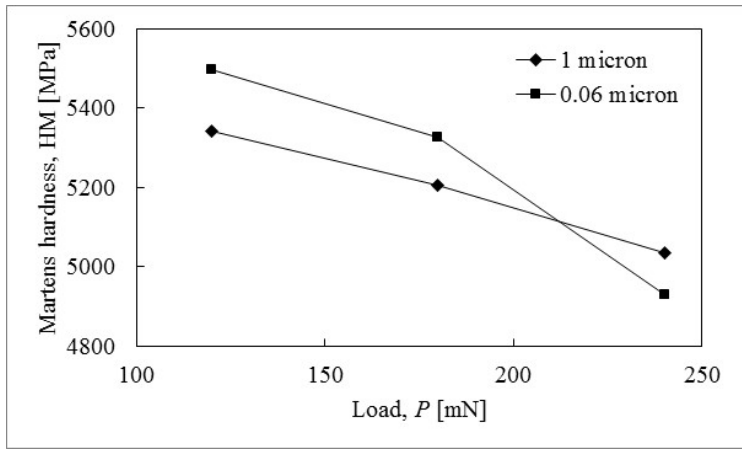

Figure 6. Effects of surface preparation on hardness at different load values. 


\subsection{Contact evolution at the indenter-material interface}

\subsubsection{Effects of the surface condition and indenter tilt}

Figure 7 and Figure 8 show the height measurement of the residual imprint left in specimens of $\mathrm{CrMoV}$ steel after polishing with colloidal silica $(0.06 \mu \mathrm{m})$ and $1 \mu \mathrm{m}$ diamond suspension. Data below the original surface has been obscured so as to show the topography around the residual imprint in more detail. Focusing on Figure 7a and Figure 8a, some recovery during unloading is evident since the side of the residual imprint deforms into a convex shape as a result of material shrinkage, which is more noticeable in the near surface strain-hardened specimen (Figure 7a). The superimposed dashed lines represent the projected area $\left(A_{p}\right)$ of the indenter at $h_{\max }$ assuming a perfectly sharp indenter, i.e. $A_{p}=24.56 h_{\max }{ }^{2}$, which in both cases is larger than the actual area $(A)$ of the residual imprint left by the Berkovich indenter measured using AFM. As summarised in Table 3, in specimens of CrMoV steel indented at $P_{\max }=240$ $\mathrm{mN}, A$ appears to recover to some extent as the average ratio $A / A_{p}=0.835$. Furthermore, it is clearly visible in Figure 8a that the near surface strain-hardened layer due to mechanical polishing, indented at the same load of $240 \mathrm{mN}$, is more prone to recovery, also confirmed by the average ratio $A / A_{p}=0.755$. In addition, from the results in Table 3 , it is possible to conclude that the recovery of the area of indentation during unloading in $\mathrm{CrMoV}$ steel is not affected by ISE, as the result of halving the indentation load is a reduction of the average $A / A_{p}$ ratio of barely 0.025 . Measurements of $A$ in Ti-6Al-4V were not possible to obtain due to its irregular topography. The surface profiles extracted from indentations on specimens of CrMoV steel along the directions $\mathrm{OA}, \mathrm{OB}$ and $\mathrm{OC}$ are presented in Figure $7 \mathrm{~b}$ and Figure $8 \mathrm{~b}$; the $Y$ coordinate relative to the maximum depth measured by AFM $\left(h_{0}\right)$ in the abscissa and the $X$ coordinate from the indenter centreline normalised by the same value $h_{0}$ in the ordinate. As expected, less noise is induced as finer particles are used for polishing. Generally, materials with limited capacity to strain-harden are more likely to pile-up, yet comparing these figures suggests that this is not the case for a material exposed to a near surface strain-hardening resulting from the metallographic procedure, provided that the ratio of $h_{\max }$ to the thickness of the strain-hardened layer is above unity, since an equivalent degree of pile-up is observed in both specimens, i.e. $Y / h_{0} \sim 0.2$. 


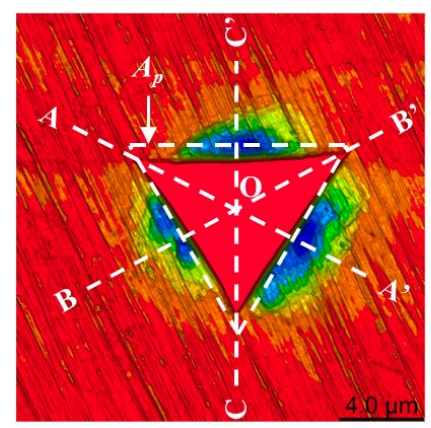

a)

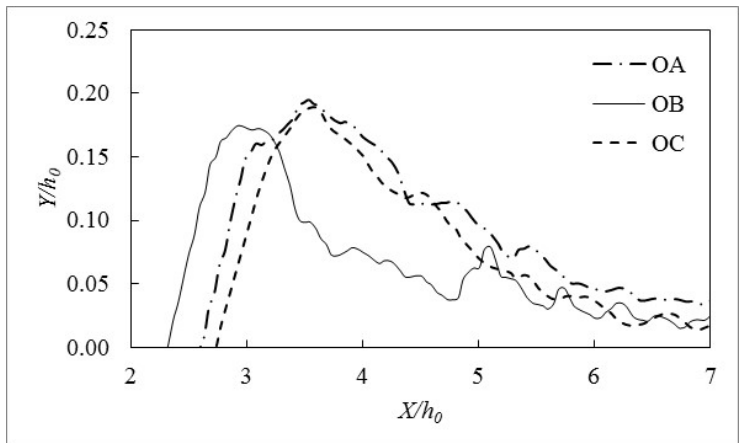

b)

Figure 7. a) Height measurement and b) pile-up patterns along the three edges of the residual imprint after the indentation at $240 \mathrm{mN}$ of a polished surface of $\mathrm{CrMoV}$ steel with $1 \mu \mathrm{m}$ diamond suspension.

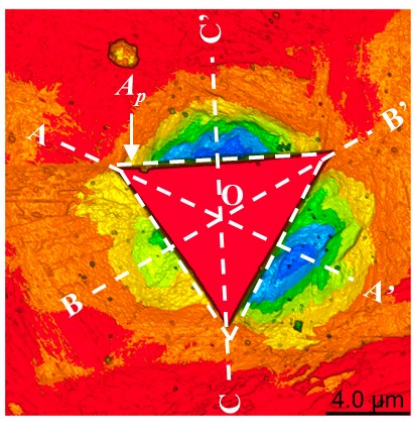

a)

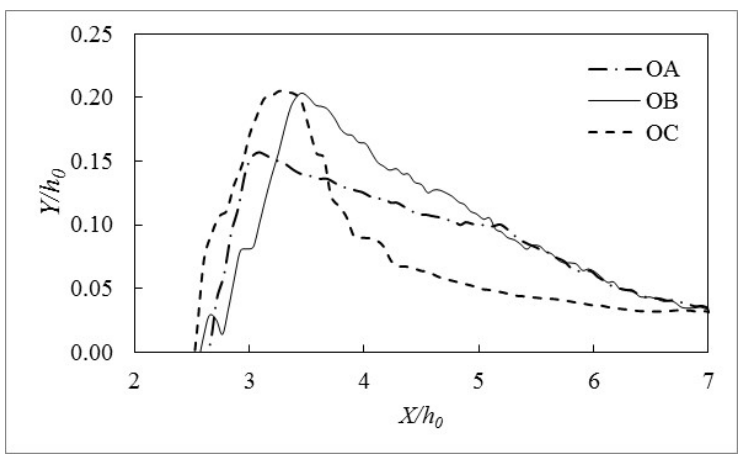

b)

Figure 8. a) Height measurement and b) pile-up patterns along the three edges of the residual imprint after the indentation at $240 \mathrm{mN}$ of a polished surface of $\mathrm{CrMoV}$ steel with $0.06 \mu \mathrm{m}$ colloidal silica.

Table 3. Imprint area of indentation measured via AFM $(A)$

\begin{tabular}{cccc}
\multicolumn{4}{c}{ compared with the area projected by an ideal indenter $\left(A_{p}\right)$ at $h_{\max }}$. \\
\hline \hline Indentation & $A\left[\mu \mathrm{m}^{2}\right]$ & $A_{p}\left[\mu \mathrm{m}^{2}\right]$ & $A / A_{p}$ \\
\hline CrMoV $240 \mathrm{mN}^{*}$ & 29.83 & 39.39 & 0.76 \\
& 34.84 & 46.58 & 0.75 \\
\hline CrMoV $240 \mathrm{mN}$ & 39.00 & 47.41 & 0.82 \\
& 37.10 & 43.41 & 0.85 \\
\hline \multirow{2}{*}{ CrMoV $120 \mathrm{mN}$} & 15.42 & 18.66 & 0.83 \\
C110 $120 \mathrm{mN}$ & 17.56 & 22.29 & 0.79 \\
\hline C110 36 mN & 88.86 & 89.12 & 0.99 \\
& 79.90 & 76.24 & 1.05 \\
\hline \hline
\end{tabular}

* Specimen polished with $1 \mu \mathrm{m}$ diamond suspension 
Figure 9 shows the topography of the residual imprint left by the Berkovich indenter pressed with a load of $120 \mathrm{mN}$ on the surface of $\mathrm{C} 110$ copper. In contrast to the behaviour of CrMoV upon unloading, the measured area $A$, although visibly deformed, closely matches $A_{p}$ (superimposed in Figure 9a), i.e. the average $A_{p} / A$ ratio is close to unity. This is in accordance with Tabor's $[22,23]$ observation that for some metals, the contact radius left in the surface by a conical indenter does not recover during unloading, that is, only the depth recovers. The case in which the ratio $A_{p} / A$ exceeded unity (shown in Figure 9a) results from the misalignment of the indenter relative to the normal of the surface. From geometry, a maximum tilt angle of $1.8^{\circ}$ is measured between the experimental points along the edge OA', and the edge of an ideal, perfectly sharp indenter after the removal of the load $(P=0)$ as illustrated in Figure $9 \mathrm{~b}$. Similarly to $\mathrm{CrMoV}$ steel, in $\mathrm{C} 110$ copper, any recovery during unloading appears to be independent from ISE as at lower loads, e.g. $36 \mathrm{mN}, A$ is not less than $A_{p}$. The increased ratio $A_{p} / A$ results from a more pronounced misalignment in excess of $3.7^{\circ}$ that consequently leaves a largely deformed imprint as can be seen in Figure 10a. The misalignment of the indenter centreline from the normal of the surface is caused by a combination of the non-flat surface produced during the metallographic preparation and the misalignment between the centrelines of the sample mounting and instrument holder.
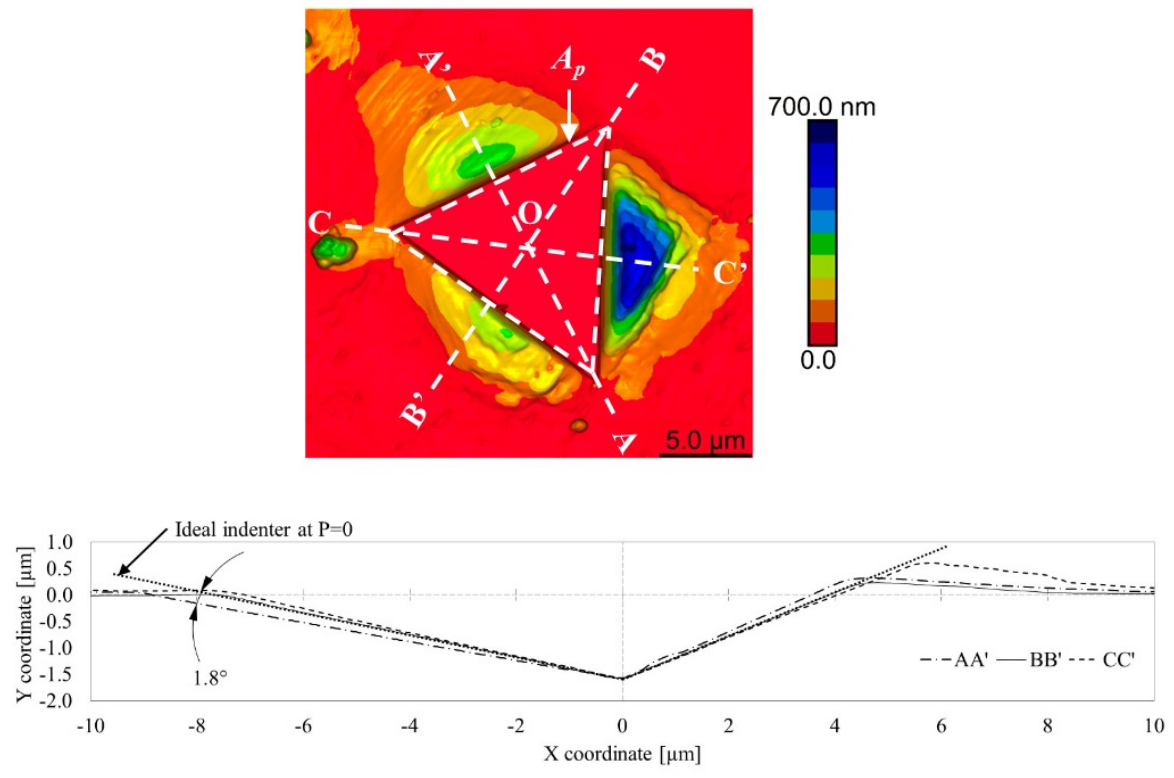

Figure 9. a) Height measurement and b) cross-section profile of the imprint in $\mathrm{C} 110$ formed by a Berkovich indenter loaded to $120 \mathrm{mN}$. 

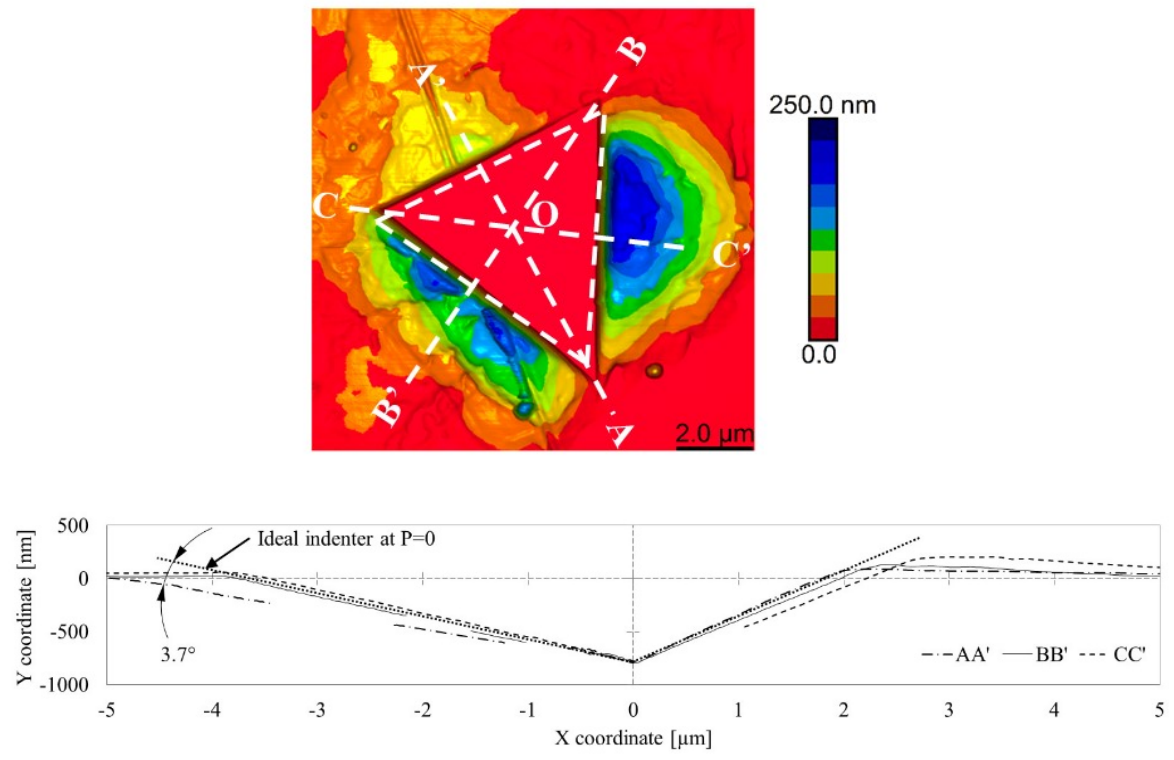

Figure 10. a) Height measurement and b) cross-section profile of the imprint in C110 formed by a Berkovich indenter loaded to $36 \mathrm{mN}$.

Therefore, in order to discard the arbitrary tilt between the normal of the sample surface and the centreline of the indenter as the main cause of the uneven pile-up patterns along the three edges, full 3D FE simulations were performed assuming an indenter tilted by $2^{\circ}$ around the axes +U1 (Figure 11a), +U3 (Figure 11c) and both around +U1 and +U3 (Figure 11e). The other two cases in which the indenter is tilted around U3 in the negative direction, i.e $2^{\circ}$ around $-\mathrm{U} 3$, and $2^{\circ}$ around both $+\mathrm{U} 1$ and $-\mathrm{U} 3$, were also analysed yet the effects of the indenter tilt was observed to a lesser extent compared with their counterparts and hence, are not included in Figure 11. It is evident from this figure that a misaligned indenter not only distorts the shape of the residual imprint but the effect is also reflected in maximum pile-up height $\left(h_{\text {peak }}\right)$ as observed in the corresponding figures (Figure $11 \mathrm{~b}, \mathrm{~d}$ and $\mathrm{f}$ ). For instance, the effects of indenter tilt were maximum along the edge $\mathrm{OB}^{\prime}$ of the residual imprint formed after an indentation performed with an indenter tilted $2^{\circ}$ around both the +U1 and +U3 axes, as the maximum pileup was observed to be $7.4 \%$ lower in relation to that of an indentation performed with a perfectly aligned indenter. 

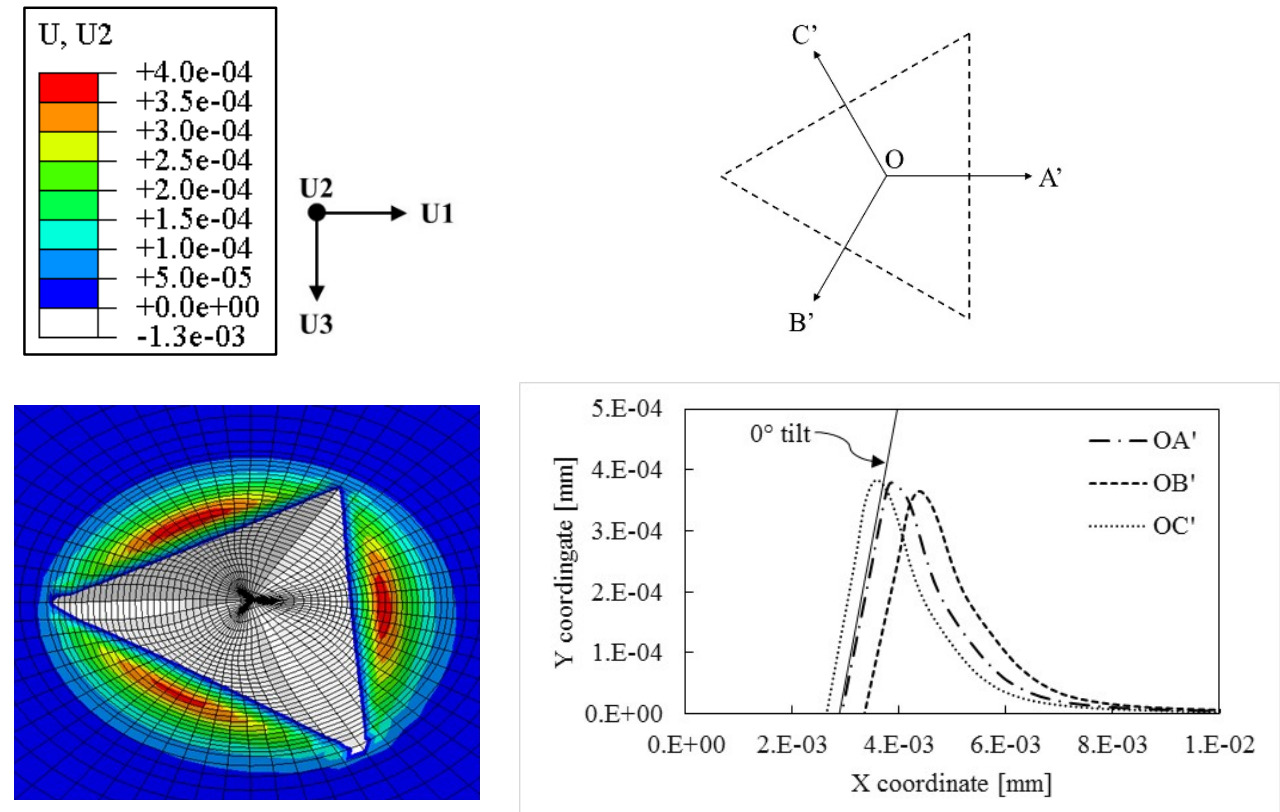

a)

b)
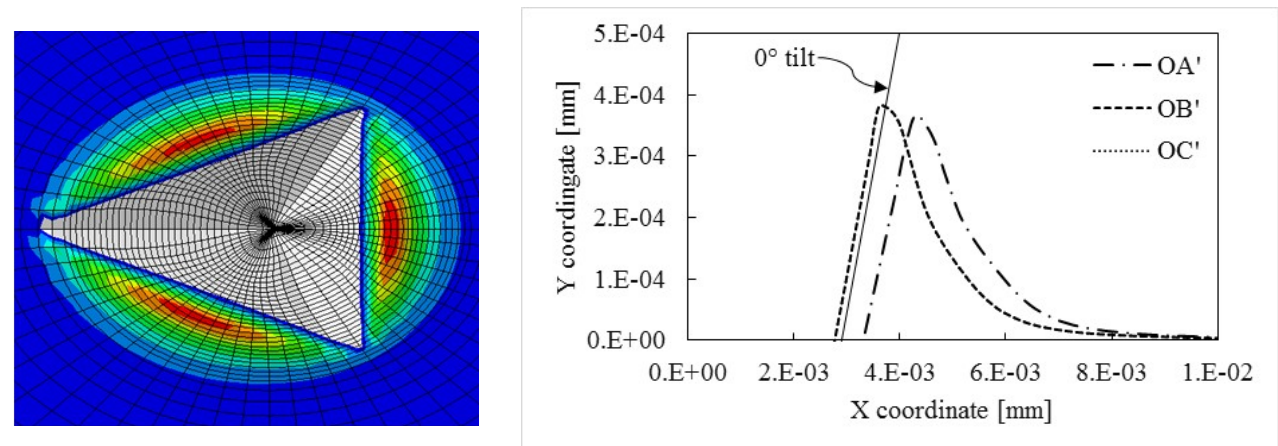

c)

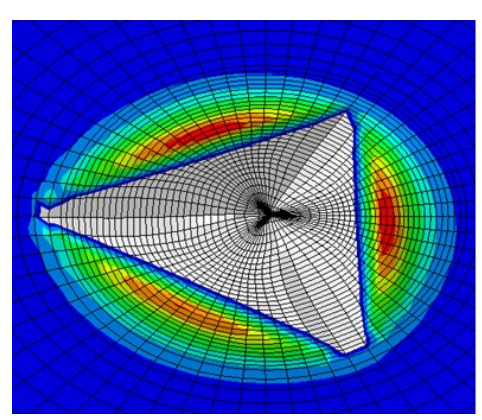

d)

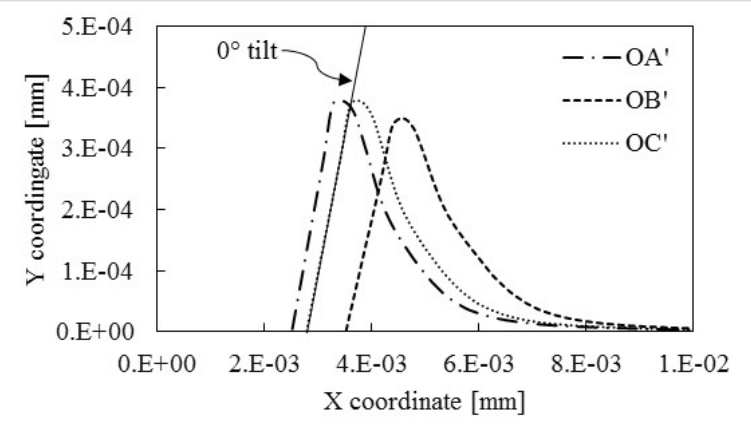

e)

f)

Figure 11. Residual imprint left by an indenter tilted with respect to the normal of the surface by $2^{\circ}$ around $\left.\left.a, b\right) \mathrm{U} 1, \mathrm{c}, \mathrm{d}\right) \mathrm{U} 3$, and e, f) U1 and U3.

This is related to the shape of the plastic strain field generated beneath the indenter and could be better explained for the case of tilting around an individual axis, e.g. the U3 axis as follows: The mechanism by which the pile-up phenomenon occurs involves local plasticity at different strain levels, being higher along the edges of the indenter and increasing towards the tip, as can 
be seen in Figure 12a for the case of no tilting. Therefore, a high strain concentration is located beneath the indenter, decreasing in magnitude beyond the points of contact at the specimenindenter interface as shown in Figure $12 \mathrm{~b}$. The result is that the severely strain-hardened material causes the surrounding material to displace plastically and pile-up around the indenter due to the incompressibility of plastic deformation. Comparing the equivalent plastic strain along section $\mathrm{OA}^{\prime}$ in Figure 13a, the region within the contact zone (indicated by vertical dashed lines in Figure 13a and arrows in Figure 13b) is strain hardened to a greater and lesser degree when the indenter is tilted $2^{\circ}$ around the positive and negative U3 axis respectively, compared with that of the case of a perfectly aligned indenter. Therefore, an indenter tilted $2^{\circ}$ around the positive and negative axis resulted in a shift of the point of maximum pile-up by $3 \%$ below and $0.4 \%$ above, respectively, the maximum pile-up reached when the indenter is perfectly aligned, as can be seen in Figure 13a. However, the accuracy of the quantitative information presented here is limited by the capacity of the linear elements to represent the contact conditions. The tilt case of $2^{\circ}$ around $+\mathrm{U} 3$ is qualitatively in contrast with Figure 9 and Figure 10, as the material piles-up higher at the edge opposite to the corner at which the indenter is tilting, which suggests that the structural arrangement of the indented material may also contribute to the asymmetry in the pile-up patterns.

a)
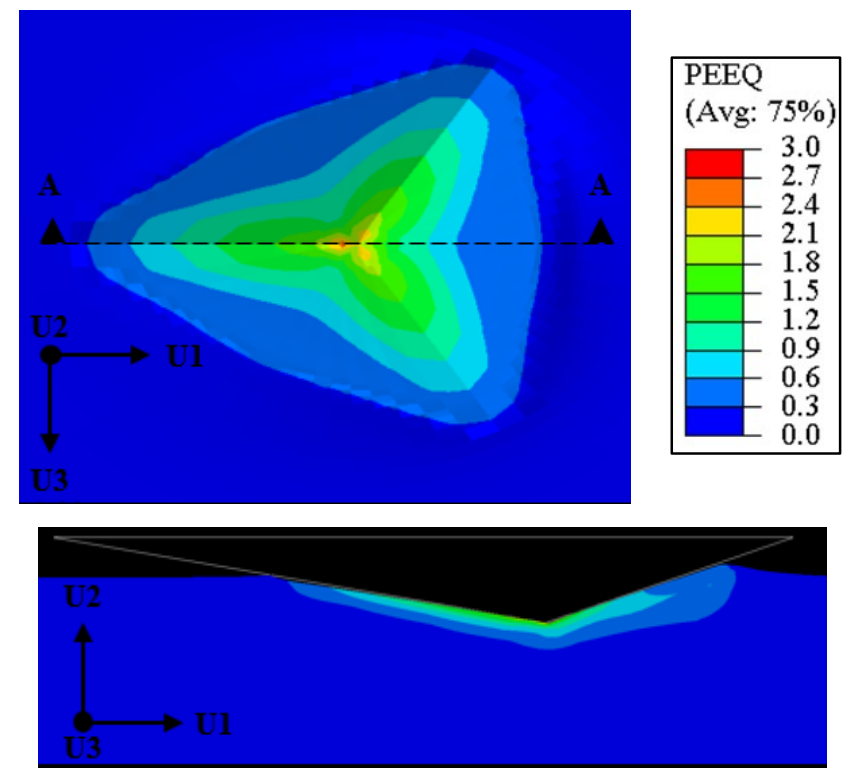

Figure 12. a) Top view and b) cut view AA showing the equivalent plastic strain beneath a perfectly sharp indenter and perfectly aligned with the normal of the surface. The PEEQ profile corresponds to a load $P=P_{\max }$. 
a)

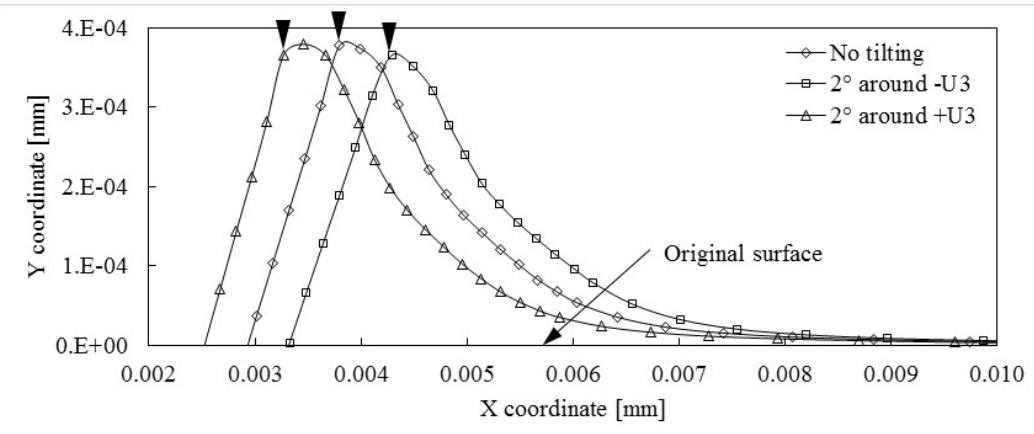

b)

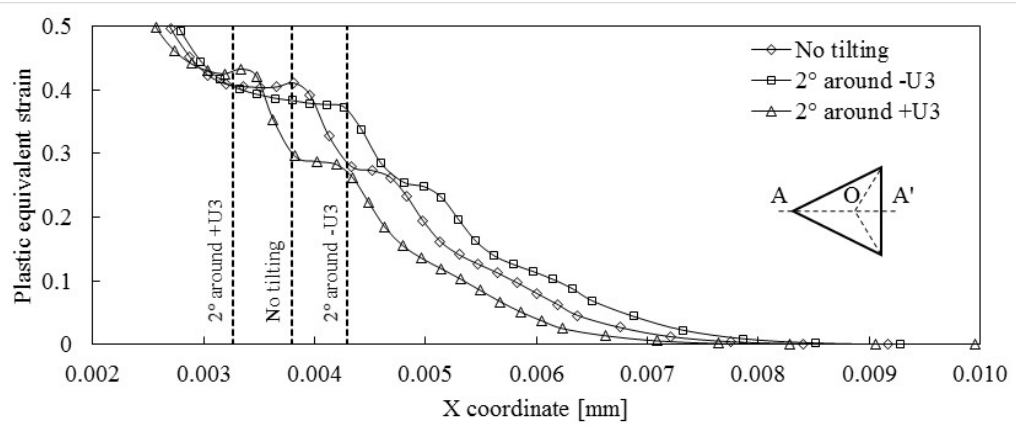

Figure 13. a) Pile-up patterns and b) plastic equivalent strain (PEEQ) along section OA.

\subsubsection{Effects of the microstructure on the six-fold symmetry of Berkovich indentations}

Besides the disturbance of the pile-up pattern resulting from experimental uncertainty, the contact evolution at the indenter-material interface may be strongly dependent on the crystallographic orientation of individual grains, the mismatch of material properties from grain to grain and the directionality of these properties, i.e. anisotropy.

Recalling from section 3.1, the grain sizes in C110 copper range from 30 to $100 \mu \mathrm{m}$ and thus some indentations may be situated entirely within a single grain. The predominant piling-up of material at one of the edges of the triangular impression of indentation may be explained by the strong dependency of single grains of high purity copper on the crystallographic orientation of the indented surface [14]. Furthermore, copper is known for its highly anisotropic behaviour with Young's modulus values of 66.7, 130.3 and 191.1 GPa along the [100], [110] and [111] crystallographic orientations, respectively [24].

Altogether, the misalignment of the indenter and the dependency of plastic flow on the crystallographic orientation results in a loss of indentation symmetry, e.g. the one-sixth fold in a Berkovich indenter, which makes the data difficult to interpret. As observed in Figure 9, the maximum pile-up value, along the edge $\mathrm{OA}^{\prime}$ after indentation at $120 \mathrm{mN}$, is in excess of $70 \%$ 
above the maximum height at the other two edges ( $\mathrm{OB}^{\prime}$ and $\mathrm{OC}^{\prime}$ ). A consistent trend is observed after indentation with a maximum load of $36 \mathrm{mN}$, where the discrepancy between highest and lowest value is approximately $62 \%$ as shown in Figure 10 . Nonetheless, the degree of piling-up appears independent of ISE as it was found that the ratio $h_{\text {peak }} / h_{0}$ for the two indentations at each indentation load, i.e. 120 and $36 \mathrm{mN}$ were very similar as reported in Table 4. This observation was also shown by the residual imprints left in $\mathrm{CrMoV}$ steel at indentation loads of 240 and $120 \mathrm{mN}$. Both values, $h_{\text {peak }}$ and $h_{0}$, included in Table 4 represent respectively the average of the maximum pile-up height and maximum depth measured from the pile-up profiles extracted from the three directions of the triangular residual imprint.

Table 4. Ratio of maximum pile-up to maximum indentation depth as measured via atomic force microscopy.

\begin{tabular}{cccc}
\hline \hline Indentation & $h_{0}[\mu \mathrm{m}]$ & $h_{\text {peak }}[\mu \mathrm{m}]$ & $h_{\text {peak }} / h_{0}$ \\
\hline \hline \multirow{2}{*}{ C110 120 mN } & 1.68 & 0.39 & 0.23 \\
& 1.57 & 0.39 & 0.25 \\
\hline \multirow{2}{*}{ 11 $1036 \mathrm{mN}$} & 0.79 & 0.14 & 0.18 \\
& 0.83 & 0.18 & 0.22 \\
\hline \multirow{2}{*}{ CrMoV $240 \mathrm{mN}$} & 1.07 & 0.15 & 0.14 \\
& 1.00 & 0.16 & 0.16 \\
\hline \multirow{2}{*}{ CrMoV $120 \mathrm{mN}$} & 0.65 & 0.08 & 0.12 \\
& 0.69 & 0.12 & 0.17 \\
\hline \hline
\end{tabular}

The dependency of plastic flow on the microstructure is expected to reduce as the number of grains in contact with the indenter increases as the specimen behaves more isotropically, given that the crystallographic orientations of the individual grains in a polycrystalline material are totally random [24]. Therefore, a macrohardness test using a Vickers indenter loaded at $20 \mathrm{kgf}$ was performed on the C110 copper material. The micrograph presented in Figure 14a reveals apparent slip lines randomly oriented as a larger number of grains were indented and thus the contact response resembles more that of a continuum, isotropic material. This consequently results in a more homogeneous plastic deformation as observed in the topographic image (Figure 14b) where the expected eight-fold symmetry of deformation is better approached for this indentation case. The height profile in Figure 14c, extracted from scans along the diagonals of the residual imprint, shows that plastic flow during indentation was constrained at equivalent distances from the centreline of the indenter. Still, the point of maximum pile-up is asymmetric ( $\mathrm{C}$ in Figure $14 \mathrm{~b})$ as the average of the diagonals of indentation $\left(d_{a v}=592 \mu \mathrm{m}\right)$ is not 
significantly larger than the grain size $(30-100 \mu \mathrm{m})$ and consequently, the dependency of plastic flow to the microstructure has not completely vanished in this case. The indented surface was measured using an Alicona G5 focus variation instrument as the macroindentation could not be conveniently imaged in the AFM.

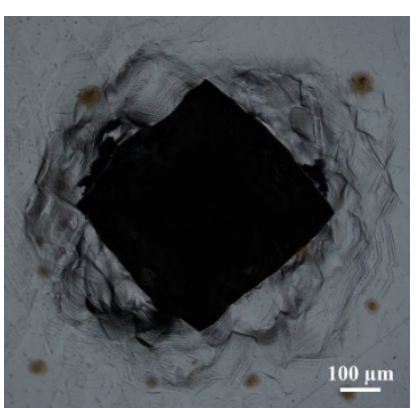

a)

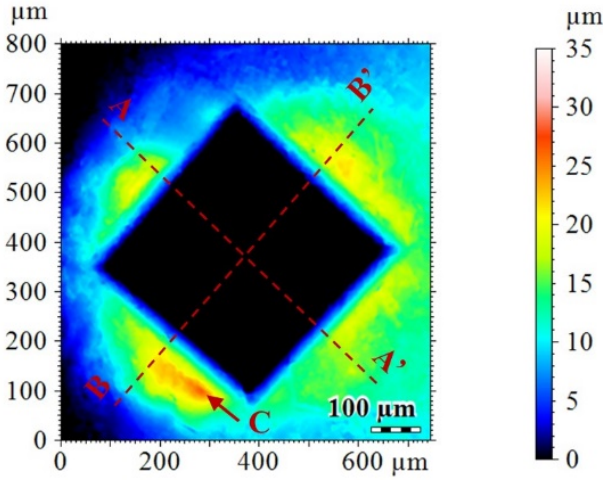

b)

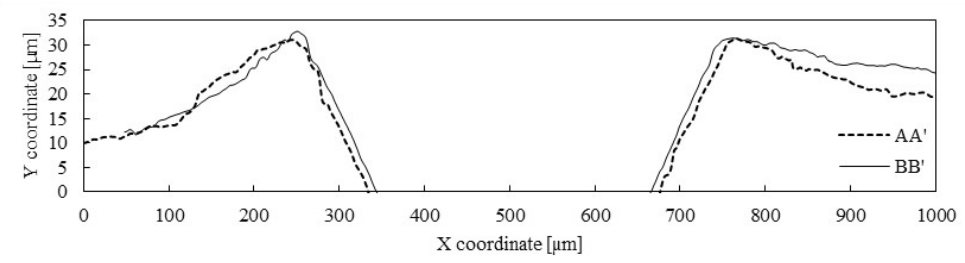

c)

Figure 14. a) Optical microscope and b) surface topography after a macrohardness Vickers indenter test at $20 \mathrm{kgf}$ performed on the $\mathrm{C} 110$ specimen. The c) surface profile has been extracted from scans along the two diagonals of indentation.

The data extracted from Ti-6Al-4V is more drastically affected as the measured volume is a mixture of $\alpha$-Ti and $\beta$-Ti phases, both of significantly different material properties. For instance, the elastic modulus of $\alpha$-Ti and $\beta$-Ti are $132.2 \pm 12.2$ and $81.1 \pm 13.1 \mathrm{GPa}$, respectively [25], in contrast with the value of $103.1 \pm 2.1 \mathrm{GPa}$ as determined from the tensile test. As can be seen in Figure 15, free surfaces of intergranular $\beta$-Ti pile-up higher than the $\alpha$ matrix after indentation at a load of $240 \mathrm{mN}$. This irregular pile-up pattern around the indenter is also observed in indentations at lower load, e.g. $120 \mathrm{mN}$, restricted to a single grain which provides evidence of the anisotropic plastic deformation mechanism of Ti-6Al-4V and its dependency on the crystallographic orientation of the indented grain as suggested by the crystal plasticity FE simulations performed by Han et al. [26]. Such an uneven piling-up can be attributed to the different plastic behaviour of contiguous grains within the plastic zone, i.e. those visible around the indentation and those beneath the surface. 
a)
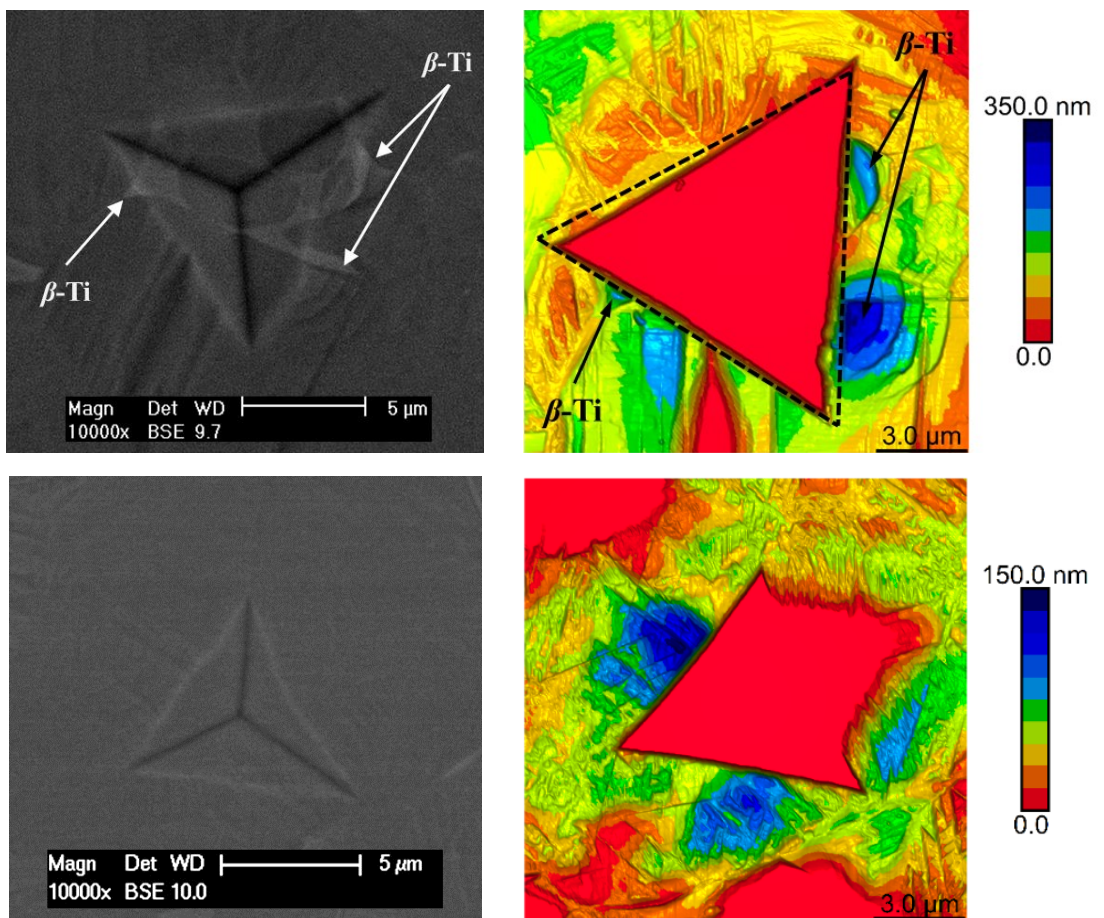

Figure 15. Residual imprint left by the Berkovich indenter pressed with a maximum load of a) $240 \mathrm{mN}$ and b) $30 \mathrm{mN}$ in Ti-6Al-4V as observed under BSE/SEM (left) and AFM (right).

\subsubsection{Effects of the microstructure on the plastic flow of material beneath the indenter}

The investigation of the residual imprint could also provide important information regarding the mechanism of plastic deformation of different microstructures such as a fine- and coarsegrained microstructure, e.g. tempered martensite in $\mathrm{CrMoV}$ steel and $\mathrm{C} 110$ copper, respectively, and a two-phase microstructure, e.g. Ti-6Al-4V. For clarity, Figure 8a and Figure 9a are presented in Figure 16 with additional information. From Figure 17a, it can be seen that the AFM measurement shows that the volume of plastically displaced material was confined to a region adjacent to the indenter-material interface, identified as region $\mathrm{C}$, and reached a maximum pile-up height within region $\mathrm{A}$. The pile-up height decreased away from the indenter centreline and towards the intersections of the indenter edges, i.e. the corners of the triangle. Also it can be seen that in the neighbourhood of the corners of the triangle the material does not show a dominant plastic flow behaviour, i.e. piling-up or sinking-in; this behaviour was delimited by region B. Tempered martensite grains are relatively fine $(2-3 \mu \mathrm{m})$ compared to the area of indentation reached at $P_{\max }=0.24 \mathrm{~N}, A=39 \mu \mathrm{m}^{2}$ as reported in Table 3, and hence the plastic deformation approximated, to some extent, that of a continuum homogeneous material. The significantly coarser grains of C110 copper, which reach sizes of up to $100 \mu \mathrm{m}$, mean that indentations were likely to fall within a single grain as $A=79.9 \mu \mathrm{m}^{2}$ at $P_{\max }=0.12$ $\mathrm{N}$ and thus the anisotropic behaviour of single crystals became present. Examining the plastic flow of material in Figure 16b, it was observed that C110 copper piled-up predominantly 
towards the bisector of the side of the triangular impression within region A. Moving away from the centreline of the indenter, the height decreased until the free surface was reached beyond region $\mathrm{C}$. It was also noticeable a steeper decrease in height, compared with the imprint in $\mathrm{CrMoV}$, as the corners of the triangle are approached.

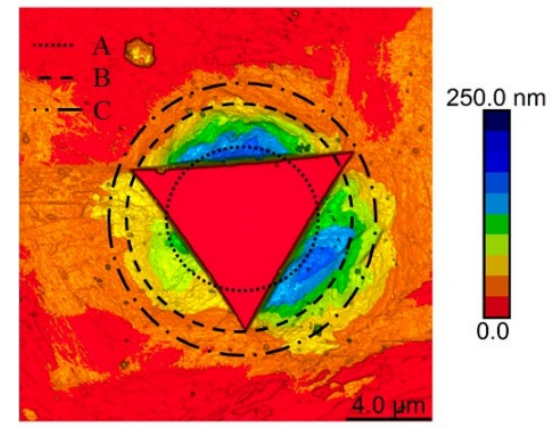

a)

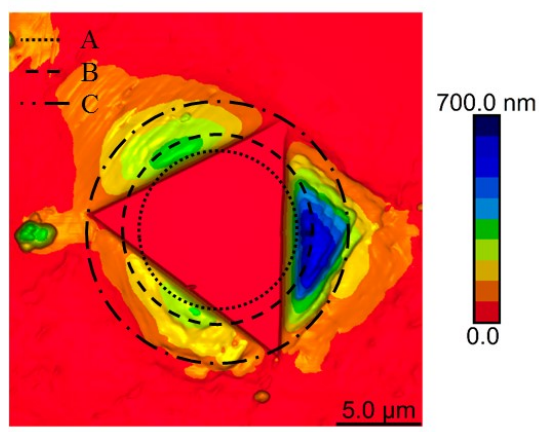

b)

Figure 16. Characteristic flow of material as revealed on the top views of the residual imprints on specimens of a) $\mathrm{CrMoV}$ steel and b) $\mathrm{C} 110$ copper.

\section{Conclusions}

The first conclusion that can be drawn seems logical, but it is sometimes overlooked: the focus of the characterisation via indentation tests is not strictly an alternative to large scale mechanical testing, but rather allows the investigation of the near surface properties of a material of interest. Given that the mechanical response of a small volume of material to indentation does not necessarily represent, nor behave as, that of the bulk material, the investigator must be aware of the gap between the behaviour of the material at different scales so as to justify whether the indentation test fulfils the objectives of the study, or otherwise.

Other key results on the measurement and use of the topography of the indentation imprint can be summarized as follows:

- The mechanical response of materials with limited capacity to strain-harden $(n<0.1)$ is relatively insensitive to the polishing procedure provided that the ratio of grit size to indentation depth is below unity. Shallow indentations, or indentations in materials with high strain-hardening may require other procedures, e.g. electropolishing.

- The effects of the indenter tilt on the pile-up pattern were investigated based on a continuum mechanics approach FE model. It was observed that an indenter tilted by $2^{\circ}$ 
towards one of the corners contributed in up to $3 \%$ to the asymmetry of the pile-up patterns. Consequently, the indenter misalignment alone does not explain the significant asymmetry piling-up in C110 copper and thus it was suggested that it was rather dominated by the crystallographic orientation of the grain tested [14, 24].

- Experiments have shown that although reasonably smooth and continuous data can be extracted with the AFM, height profiles of the surface topography are severely distorted by the contact response of individual grains, the extent and magnitude of the anisotropic effects, the crystallographic orientation of the indented grains and the atomic mismatch at the grain boundaries. Therefore, the use of the pile-up/sink-in pattern for the characterisation of the plastic behaviour is recommended only for polycrystalline materials of very small grain sizes relative to the size of indentation, or single crystals with negligible anisotropy so as to ensure symmetry of indentation.

- If anisotropic behaviour is expected, the investigator must be aware that that both the yield stress and the work-hardening as well as the Young's modulus are dependent on the crystallographic orientation of the material [24, 27] and consequently, the mechanical response measured at small scale indentation is valid only within the grain tested.

- As the physical properties of single crystals depend on the crystallographic direction relative to that in which measurements are taken, it is advisable to determine the plane of indentation and the orientation of the indenter edges relative to the crystallographic orientations.

- It is strongly advisable to perform the surface measurements immediately after indentation so as to avoid measuring any artefacts modifying the indented surface, e.g. surface contamination. On the same basis, it is recommended to perform the final polishing on the specimen immediately before the indentation test in order to avoid erroneous measurements due to surface contamination. 


\section{Acknowledgements}

The authors acknowledge the funding support from the National Council for Science and Technology (CONACyT) of Mexico.

\section{References}

1. Pethica, J.B., Hutchings, R., Oliver, W.C., Hardness measurement at penetration depths as small as $20 \mathrm{~nm}$. Philosophical Magazine A, 1983. 48(4): p. 593-606.

2. Loubet, J.L., Georges, J. M., Marchesini, O., Meille, G., Vickers Indentation Curves of Magnesium Oxide (MgO). Journal of Tribology, 1984. 106(1): p. 43-48.

3. Doerner, M.F., Nix, W. D., A method for interpreting the data from depth-sensing indentation instruments. Journal of Materials Research, 1986. 1: p. 601 - 609.

4. ISO-14577-1:2015 Metallic materials - Instrumented indentation test for hardness and materials parameters - Part 1: Test method. 2015: 1 rue de Varembé, 1211 Geneva 20 Switzerland.

5. Ma, Q., Clarke, D.R., Size dependent hardness of silver single crystals. Journal of Materials Research, 1995. 10(04): p. 853-863.

6. McElhaney, K.W., Vlassak, J.J., Nix, W.D., Determination of indenter tip geometry and indentation contact area for depth-sensing indentation experiments. Journal of Materials Research, 1998. 13(5): p. 1300-1306.

7. Liu, Y., Ngan, A.H.W., Depth dependence of hardness in copper single crystals measured by nanoindentation. Scripta Materialia, 2001. 44(2): p. 237-241.

8. Fleck, N.A., Muller, G.M., Ashby, M.F., Hutchinson, J.W., Strain gradient plasticity: theory and experiment. Acta Metallurgica et Materialia, 1994. 42(2): p. 475-487.

9. Li, H., Ghosh, A., Han, Y.H., Bradt, R.C., The frictional component of the indentation size effect in low load microhardness testing. Journal of Materials Research, 1993. 8(5): p. 1028-1032.

10. Qu, S., Huang, Y., Nix, W.D., Jiang, H., Zhang, F., Hwang, K.C., Indenter tip radius effect on the Nix-Gao relation in micro- and nanoindentation hardness experiments. Journal of Materials Research, 2004. 19(11): p. 3423-3434.

11. Sargent, P.M., Use of the Indentation Size Effect on Microhardness for Materials Characterization, in Microindentation Techniques in Materials Science and Engineering, P.J. Blau, Lawn, B.R., Editor. 1986, ASTM International: Philadelphia. p. $160-174$.

12. Lim, Y.Y., Chaudhri, M.M., The influence of grain size on the indentation hardness of high-purity copper and aluminium. Philosophical Magazine A, 2002. 82(10): p. 20712080.

13. Stelmashenko, N.A., Walls, M.G., Brown, L.M., Milman, Y.V., Microindentations on $Q$ and Mo oriented single crystals: An STM study. Acta Metallurgica et Materialia, 1993. 41(10): p. 2855-2865.

14. Wang, Y., Raabe, D., Klüber, C., Roters, F., Orientation dependence of nanoindentation pile-up patterns and of nanoindentation microtextures in copper single crystals. Acta Materialia, 2004. 52: p. 2229-2238.

15. Kucharski, S., Jarząbek, D., Depth dependence of nanoindentation pile-up patterns in copper single crystals. Metallurgical and Materials Transactions A, 2014. 45(11): p. 4997-5008.

16. Fischer-Cripps, A.C., Nanoindentation. Mechanical Engineering Series. 2004, New York: Springer 
17. Kuhn, H., Dana, M., ASM handbook. Volume 8, Mechanical testing and evaluation. 2000, ASM International: Materials Park, OH.

18. ISO 4287:1997 Geometrical Product Specifications (GPS) -- Surface texture: Profile method -- Terms, definitions and surface texture parameters. 1997: 1 rue de Varembé, 1211 Geneva 20 Switzerland.

19. Bruker, NanoScope Analysis1.50.

20. Larsson, P.-L., Giannakopoulos, A. E., Söderlund E., Rowcliffe, D. J., Vestergaard, R., Analysis of berkovich indentation. International Journal of Solids and Structures, 1996. 33(2): p. 221-248.

21. Bhadeshia, H., Honeycombe, R., Steels: Microstructure and properties. 2006, Oxford: Butterworth-Heinemann,.

22. Tabor, D., A Simple Theory of Static and Dynamic Hardness. Proceedings of the Royal Society of London A, 1948. 192: p. 247-274.

23. Stillwell, N.A., Tabor, D., Elastic Recovery of Conical Indentations. Proceedings of the Physical Society, 1961. 78(2): p. 169-179.

24. Callister, W.D., Materials science and engineering : an introduction. 7th ed. 1940, Hoboken, N.J. :: John Wiley \& Sons,.

25. Sen, I., Ramamurty, U., Elastic modulus of Ti-6Al-4V-xB alloys with $B$ up to 0.55 wt.\%. Scripta Materialia, 2010. 62(1): p. 37-40.

26. Han, F., Tang, B., Kou, H., Li, J., Feng, Y., Experiments and crystal plasticity finite element simulations of nanoindentation on Ti-6Al-4V alloy. Materials Science and Engineering A, 2015. 625: p. 28-35.

27. Meyers, M.A., Mechanical behavior of materials. 2009, Cambridge: Cambridge University Press. 